\title{
DISTRIBUSI PENDAPATAN PETANI EKS UPP TCSDP DI DESA SIALANG KAYU BATU KECAMATAN BUNUT KABUPATEN PELALAWAN
}

\author{
Indo Muharram Afdillah, Eliza, Shorea Khaswarina \\ Jurusan Agribisnis, Fakultas Pertanian, Universitas Riau \\ Email: indomuharam@gmail.com
}

\begin{abstract}
The Ex UPP TCSDP Farmers are the farmers who get the government assistance in agriculture in 1992.UPP TCSDP stands for Unit of Project Implementation of Tree Crop Smallholder Development Program which is this program is the government assistance to plantation farmers (rubber, coconut, sugarcane) funded by World Bank by applying management mergers related to technology, production and marketing, in 1998 is the last planting, so it is called Ex of UPP TCSDP. This research aims to analyze the sources and the income structure and to observe the distribution and inequality of income of The Ex UPP TCSDP Farmer. This research took place in SialangKayuBatu Village, Bunut Sub-District, PelalawanDistrict. The results showed that the income source was divided into two income source from agricultural and non-agricultural. Total income from agricultural per year was Rp. 1.685.603.901 (89,95\%), while total income from non-agricultural per year was Rp. 188.400.000/year (10,05\%). The highest income distribution was in the Ex UPP TCSDP Farmers in the middle class as many as 9 farmers with total proportion of income per year amount $R p .769 .422 .455$ (41,06\%), while for the lowest income proportion was the Ex UPP TCSDP Farmers in the lowest class as many as 9 farmers with total proportion of income amount Rp. 409.293 .513 (21,84\%).The Index Value of Gini Ratio was in low or mild inequality that equal to 0,20. It is indicated that, the income equalityof The Ex UPP TCSDP Farmer in SialangKayuBatu village Bunut Sub-District Pelalawan District was good.
\end{abstract}

Keywords: farmer, UPP TCSDP, income distribution, indeks gini ratio

\begin{abstract}
Abstrak : Petani Eks UPP TCSDP adalah petani yang mendapatkan bantuan pemerintah di bidang pertanian pada tahun 1992. UPP TCSDP merupakan singkatan dari Unit Pelaksanaan Proyek Tree Crop Smallholder Development Program dimana program ini berupa bantuan yang diberikan pemerintah kepada petani perkebunan (karet, kelapa, tebu) yang dibiayai oleh Bank Dunia dengan melaksanakan penggabungan manajemen yang berkaitan dengan teknologi, proses produksi, dan pemasaran, pada tahun 1998 merupakan tanam terakhir sehingga disebut Eks UPP TCSDP. Penelitian ini bertujuan untuk menganalisis sumber-sumber dan struktur pendapatan serta distribusi dan ketimpangan pendapatan petani Eks UPP TCSDPdi Desa Sialang Kayu Batu Kecamatan Bunut Kabupaten Pelalawan.. Penelitian dengan metode survey dan pengambilan responden secara simple random sampling. Hasil penelitian menunjukkan bahwa sumber pendapatan ada duayaitu pendapatan dari pertanian dan non pertanian.Total pendapatan dari pertanian per tahun sebesar Rp. 1.685.603.901(89,95\%), sedangkan total pendapatan dari non pertanian sebesar Rp.188.400.000 (10,05\%). Distribusi pendapatan tertinggi terdapat pada petani Eks UPP TCSDP golongan menengah sebanyak 9 orang dengan total proporsi jumlah pendapatan per tahun sebesar Rp.769.422.455 (41,06\%), sedangkan untuk proporsi pendapatan terendah sebanyak 9 orang dengan total proporsi jumlah pendapatan per tahun sebesar Rp. 409.293 .513 (21,84\%).Nilai Indeks Gini Ratio berada pada
\end{abstract}


Indo Muharram A., Eliza, Shorea Khaswarina : Distribusi Pendapatan Petani ...

ketimpangan rendah atau ringan yaitu sebesar 0,20 , artinya kemerataan pendapatan petani Eks UPP TCSDPdi Desa Sialang Kayu Batu Kecamatan Bunut Kabupaten Pelalawan tergolong baik.

Kata kunci : petani, UPP TCSDP, distribusi pendapatan, indeks gini rasio

\section{PENDAHULUAN}

Perkebunan di Indonesia mempunyai peran dan kedudukan yang penting dan strategis baik secara ekonomi, sosial, penyerap tenaga kerja maupun peran ekologi. Pengelolaan perkebunan pada saat ini masih mengandalkan dan bertumpu pada melimpahnya sumber daya manusia yang relatif murah. Efisiensi, produktifitas, kualitas, keberlanjutannya yang masih rendah, kurang memiliki keunggulan kompetitif serta lemahnya pengembangan produk yang ditandai oleh ekspor yang sebagian besar berupa produk primer (Suswatiningsih, 2008).

Perkebunan dapat dijadikan sektor pengembangan pembangunan berkelanjutan, karena prosesnya berlangsung secara berkelanjutan yang ditopang oleh sumber daya alam, kualitas lingkungan dan manusia. Selain, itu pembangunan perkebunan merupakan bagian integral dari pembangunan nasional yang berperan dalam perbaikan struktur ekonomi.

Luas areal karet Indonesia meningkat dari tahun 2014 ke tahun 2015 seluas 3.606.245 Hapada tahun 2014, dan pada tahun 2015 seluas 3.621.587 Ha (Direktorat Jenderal Perkebunan, 2016) meningkat sebesar $0,42 \%$. Walaupun negara Indonesia memiliki luas lahan karet terluas, namun Indonesia adalah negara kedua penghasil karet di dunia.

Salah satu provinsi penghasil karet terbesar adalah Provinsi Riau, padatahun 2013 tercatat luas perkebunan karet di Riau seluas 505.264 Ha dengan jumlah produksi 354.257 ton yang mengalami peningkatan dari tahun 2012 dengan luas lahan yaitu sebesar 500.851 Ha dan jumlah produksi 350.476 ton (Badan Pusat Statistik, 2014). Untuk perkembangan perkebunan yang berkelanjutan maka pemerintah membuat program UPP TCSDP pada tahun 1992, dimana Kabupaten Pelalawan termasuk salah satu kabupaten yang mendapat bantuan dari pemerintah. Kecamatan Bunut merupakan salah satu kawasan yang termasuk dalam program UPP TCSDP Pangkalan Kuras.
Unit Pelaksanaan Proyek (UPP) Tree Crop Smallholder Development Program (TCSDP) merupakan bantuan yang diberikan pemerintah kepada petani perkebunan (karet, kelapa, tebu) yang dibiayai oleh Bank Dunia yaitu penggabungan manajemen yang berkaitan dengan teknologi, proses produksi, dan pemasaran. Bantuan Program UPP TCSDP yang diberikan kepada desa ini berupa bantuan sarana produksi seperti bibit, alat pertanian, pupuk, dan uang untuk membuka lahan. Tahun tanam terakhir program UPP TCSDP adalah tahun 1998, dan disebut sebagai program Eks UPP TCSDP. Desa Sialang Kayu Batu merupakan salah satu desa yang mendapatkan program UPP TCSDP.

Desa Sialang Kayu Batu merupakan salah satu desa yang mendapatkan program UPP TCSDP, Desa Sialang Kayu Batu memiliki 86 orang petani Eks UPP TCSDP. Semenjak adanya program UPP TCSDP kehidupan petani karet di Desa Sialang Kayu Batu mulai meningkat pendapatannya. Petani karet Desa Sialang Kayu Batu mulai mengembangkan perkebunan karet swadaya dan juga kelapa sawit dengan cara yang benar dan tepat dengan pedoman dari para penyuluh dari pihak UPP TCSDP. Saat ini sektor perkebunan menjadi sentra mata pencaharian penduduk di Desa Sialang Kayu Batu. Hal ini dapat diketahui dengan banyaknya perkebunan karet dan kelapa sawit di desa tersebut.

Tujuan dari penelitian ini adalah (1) menganalisis sumber-sumber pendapatan petani dan struktur pendapatan petani Eks UPP TCSDPdi Desa Sialang Kayu Batu Kecamatan Bunut Kabupaten Pelalawan. (2) menganalisis distribusi dan ketimpangan pendapatan Petani Eks UPP TCSDP di Desa Sialang Kayu Batu Kecamatan Bunut Kabupaten Pelalawan.

\section{METODE PENELITIAN}

Penelitian dilakukan di Desa Sialang Kayu Batu Kecamatan Bunut Kabupaten Pelalawan. Lokasi ini dipilih dikarenakan sebagian besar penduduk merupakan bermata pencaharian dari 
perkebunan. Waktu penelitian dari bulan Desember 2016 - Mei 2017.

Metode pengambilan data dengan metode survei menggunakan kuesioner. Jumlah petani Eks UPP TCSDP adalah 86orang petani, diambil sampel sebanyak 25 persen yaitu sebanyak 22 orang petani, Penentuan sampel ini didasarkan atas pertimbangan karakteristik petani sampel yang bersifat homogen.

Sumber data dalam terbagi dua, yaitu data prmer dan data sekunderData primer diperoleh dari hasil wawancara langsung dengan petani.Data sekunder berasal dari Instansi pemerintahan dan swasta serta sumber literatur lainnya yang terkait dengan penelitian.

Pendapatan rumah tangga petani dihitung melalui Struktur pendapatan yang berdasarkan sumber pendapatan rumah tangga dengan rumus (Widodo,1990):

Keterangan :

$$
\mathrm{Yrt}=\left(\mathrm{Y}_{\mathrm{i} 1}+\mathrm{Y}_{\mathrm{i} 2}\right)
$$

Yrt = Pendapatan rumah tangga petani (Rp/tahun).

$\mathrm{Y}_{\mathrm{i} 1}=$ Pendapatan pertanian (Rp/tahun)

$\mathrm{Y}_{\mathrm{i} 2}=$ Pendapatan non pertanian (Rp/tahun).

Distribusi pendapatan dianalisis menggunakan koefisien Gini Rasio (Oshima dalam Widodo, 1990) untuk melihat ketimpangan pendapatan rumah tangga, rumus:

$$
\mathrm{GR}=1-\sum(\mathrm{Xi}-\mathrm{Xi}-1)(\mathrm{Yi}-\mathrm{Yi}-1)
$$

Keterangan:

GR = Gini Rasio

$\mathrm{Xi}=$ Proporsi jumlah rumah tangga kumulatif kelas i

$\mathrm{Yi}=$ Proporsi jumlah pendapatan rumah tangga kumulatif kelas i.

Kriteria ketimpangan distribusi pendapatan adalah Gini ratio< 0,3 ketimpangan pendapatan rendah atau ringan, Gini ratio 0,30,4 ketimpangan pendapatan sedang. Gini $>0,4$ ketimpangan pendapatan berat.

\section{HASIL DAN PEMBAHASAN}

\section{Karakteristik Petani Eks UPP TCSDP}

Keberhasilan kegiatan suatu usaha yang dilakukan petani ditentukan oleh potensi atau karakteristik yang dimilikinya seperti faktor fisik dan faktor sosial ekonomi. Faktor faktor tersebut dapat dilihat seperti jenis kelamin, umur, tingkat pendidikan, pengalaman usahatani, Untuk jelasnya karakteristik petani responden Eks UPP TCSDP di Desa Sialang Kayu Batu dapat dilihat Tabel 1.

Tabel 1. Karakteristik Petani Eks UPP TCSDP di Desa Sialang Kayu Batu Kecamatan Bunut Kabupaten Pelalawan tahun 2016

\begin{tabular}{llcc}
\hline No & Uraian & Jumlah Petani (Orang) & Persentase $(\%)$ \\
\hline Klasifikasi Jenis Kelamin & & \\
$1 \quad$ Laki-laki & 19 & 86,36 \\
2 & Perempuan & 3 & 13,64 \\
Klasifikasi Umur & & \\
$1 \quad$ Produktif & 20 & 90,90 \\
2 & Non produktif & 2 & 9,10 \\
Klasifikasi Tingkat Pendidikan & & \\
1 & Tidak Tamat SD & 13 & 59,09 \\
2 & Tamat SD & 5 & 22,72 \\
3 & Tamat SMP & 3 & 13,64 \\
4 & Tamat SMA & 1 & 4,55 \\
Klasifikasi Pengalaman Usahatani & & \\
1 & 20-29 Tahun & 9 & 40,91 \\
2 & 30-39 Tahun & 10 & 45,45 \\
3 & 40-49 Tahun & 3 & 13,64 \\
\hline
\end{tabular}

Sumber: Olahan Data Primer 2016 
Tabel 1 menunjukkan petani responden berjenis kelamin laki-laki terdapat 19 orang $(85,00 \%)$ lebih banyak dibandingkan berjenis perempuan yaitu 3 orang $(13,64 \%)$. Responden berjenis laki-laki merupakan tulang punggung keluarga sebagai pencari nafkah untuk memeuhi kebutuhan keluarga sedangkan perempuan yang lebih mengutamakan bekerja di rumah.selain itu laki-laki memiliki produktifitas yang lebih tinggi dari pada wanita karena kegiatan usaha tani membutuhkan tenaga dan fisik yang kuat.

Usia produktif adalah umur yang berada dalam rentan 15-64 tahun. Usia produktif petani Eks UPP TCSDP ini berjumlah 20 orang, sedangkan usia non-produktif berjumlah 2 orang. dan dilihat dari umur rata-rata responden termasuk pada umur produktif akan berpengaruh terhadap kinerja petani selama melakukan usahatani.

Tingkat pendidikan petani sangat berpengaruh terhadap pola budidaya yang dilakukan. Tingkat pendidikan terbanyak petani adalah tidak tamat SD dengan jumlah petani sebanyak 13 orang atau 59,09\%. Klasifikasi petani dengan tingkat pendidikan terkecil berada pada tamat SMA. Jumlah petani yangtamat SMA berjumlah 1 orang atau 4,55\%. Tingkat pendidikan petani responden tergolong masih rendah, hal ini mengakibatkan daya serap dan kemampuan dalam mengambil keputusan akan menjadi lambat

Pengalaman berusaha tani akan mempengaruhi keberhasilan seorang petani, semakin lama seorang petani berusahatani maka akan semakin banyak pengetahuan yang dimiliki oleh petani tersebut, selain itu petani tersebut juga semakin terampil dalam mengelola lahan yang diusahakan. Lama pengalaman usahatani terbesar terdapat pada pengalaman berusahatani selama 30-39 tahun dengan persentase $45,45 \%$ dan lama pengalaman usahatani terkecil terdapat pada pengalaman berusahatani selama 40-49 dengan persentase $13,64 \%$.

Tabel 2.Sumber Pendapatan Petani Eks UPP TCSDP di Desa Sialang Kayu Batu Tahun 2016

\begin{tabular}{|c|c|c|c|}
\hline No & SumberPendapatan & $\begin{array}{c}\text { Jumlah } \\
\text { (Rp/Tahun) }\end{array}$ & Persentase $(\%)$ \\
\hline \multirow[t]{9}{*}{1} & PendapatanPertanian & & \\
\hline & -Karet TCSDP & 278.521 .831 & $14,86 \%$ \\
\hline & -Karet Swadaya & 414.003 .089 & $22,09 \%$ \\
\hline & -KelapaSawit & 846.678 .981 & $45,18 \%$ \\
\hline & -PengumpulSawit & 60.000 .000 & $3,20 \%$ \\
\hline & -PengumpulKaret & 86.400 .000 & $4,61 \%$ \\
\hline & Total (Rp/Tahun) & 1.685 .603 .901 & $89,95 \%$ \\
\hline & Rata-rata (Rp/Bulan) & 140.466 .992 & \\
\hline & Rata-rata (Rp/KK/Bulan) & 6.384 .863 & \\
\hline \multirow[t]{8}{*}{2} & Pendapatan Non Pertanian & & \\
\hline & -Bengkel & 12.000 .000 & $0,64 \%$ \\
\hline & -Warung & 132.000 .000 & $7,04 \%$ \\
\hline & -PerangkatDesa & 14.400 .000 & $0,77 \%$ \\
\hline & -Satpam & 30.000 .000 & $1,60 \%$ \\
\hline & Total (Rp/Tahun) & 188.400 .000 & $10,05 \%$ \\
\hline & Rata-rata (Rp/Bulan) & 15.700 .000 & \\
\hline & Rata-rata (KK/Bulan) & 713.636 & \\
\hline \multicolumn{2}{|c|}{ Total Pendapatan (Rp/Tahun) } & 1.874 .003 .901 & \\
\hline \multicolumn{2}{|c|}{ Rata-rata (Rp/KK/Tahun) } & 85.181 .996 & \\
\hline \multicolumn{2}{|c|}{ Rata-rata (Rp/KK/Bulan) } & 7.098 .500 & \\
\hline
\end{tabular}


Indo Muharram A., Eliza, Shorea Khaswarina : Distribusi Pendapatan Petani ...

Tabel 3.Jumlah Tingkat Pendapatan Petani Eks UPP TCSDP di Desa Sialang Kayu Batu Tahun 2016

\begin{tabular}{cccc}
\hline No & Tingkat Pendapatan (Rp) & Jumlah (orang) & Persentase (\%) \\
\hline 1 & $26.743 .574-64.379 .454$ & 9 & 40 \\
2 & $64.724 .010-123.215 .962$ & 9 & 40 \\
3 & $144.081 .371-206.434 .400$ & 4 & 20 \\
\hline & Total & 22 & 100 \\
\hline
\end{tabular}

Sumber: Olahan Data Primer 2016

Sumber dan Struktur Pendapatan Petani Eks UPP TCSDP Di Desa Sialang Kayu Batu Kecamatan Bunut Kabupaten Pelalawan

Pendapatan rumah tangga adalah total pendapatan dari seluruh anggota keluarga yang berasal dari berbagai sumber kegiatan produktif yang dilakukan pada periode tertentu. Pendapatan rumah tangga yang diperoleh berasal dari pekerjaan utama dan pekerjaan sampingan, serta usaha sub sistem dari semua anggota keluarga.

Tabel 2 menunjukkan sumber pendapatan rumah tangga petani Eks UPP TCSDP dari sektor pertanian totalnya per tahunsebesar Rp. 1.685.603.901 (89,95\%) dan rata-rata pendapatan per bulan sebesar Rp. 140.466.992. atau sebesar Rp 6.384 .863 /KK/bulan. Sedangkan pendapatan yang berasal dari sektor non pertanian dengan total pendapatan setahun sebesar Rp. 188.400.000 $(10,05 \%)$, dan rata-rata pendapatan perbulan sebesar Rp. 15.700.000 atau Rp. 713.636 /KK/bulan. Total pendapatan petani Eks UPP TCSDP di Desa Sialang Kayu Batu baik dari sektor pertanian dan non pertanian selama setahun sebesar Rp1.874.003.901 dengan ratarata pendapatan petani sebulan sebesar Rp7.098.500.

Tabel 2 menunjukkan sebagian besar pendapatan yang diperoleh petani Eks UPP TCSDP di desa Sialang Kayu Batu Kecamatan Bunut Kabupaten Pelalawan berasal dari sektor pertanianya itu lahan karet Eks UPP TCSDP dan swadaya, kelapa sawit, pengumpul sawit, dan pengumpul karet Sektor pertanian merupakan sektor yang sangat berperan dalam memberikan sumbagsih terhadap pendapatan petani Eks UPP TCSDP karena masyarakat di Desa Sialang Kayu Batu menjadikan sektor pertanian sebagai mata pencaharian utama, akan tetapi sektor non pertanian juga sangat membantu dalam penambahan pendapatan petani walaupun tidak terlalu besar.

Distribusi Pendapatan Petani Eks UPP TCSDP Di Desa Sialang Kayu Batu Kecamatan Bunut Kabupaten Pelalawan

Keberhasilan pembangunan suatu daerah tidak hanya diukur dari pertumbuhan ekonomi yang tinggi, melainkan diukur beberapa variabel dan indikator ekonomi lainnya, karena pertumbuhan ekonomi yang tinggi belum tentu mencerminkan pendapatan perkapita yang diterima masyarakat yang tinggi dan distribusi pendapatan yang adil dan merata diantara masyarakat.

Distribusi pendapatan merupakan salah satu ukuran yang digunakan untuk menunjukkan tingkat kemerataan pendapatan yang diterima oleh masyarakat. Distribusi pendapatan yang adil (merata) dikalangan masyarakat pada suatu daerah, merupakan salah satu dari sasaran daerah untuk mensukseskan pembangunan.

Tabel 3 menunjukkan variasi jumlah pendapatan petani Eks UPP TCSDP di Desa Sialang Kayu Batu yang terbagi dalam 3 golongan yaitu $40 \%$ golongan terendah, $40 \%$ golongan menengah dan $20 \%$ golongan tertinggi. Golongan terendah yang pendapatannya sebesar Rp.26.743.574 sampai Rp. 64.379.454 per tahun sebanyak 9 orang petani sampel di Desa Sialang Kayu Batu. Selanjutnya golongan menengah dengan pendapatan sebesar Rp. 64.724 .010 sampai Rp. 123.215.962 pertahun sebanyak 9 orang petani dan golongan tertinggi dengan jumlah sampel sebanyak 4 orang petani yang memperolah pendapatan sebesar Rp. 144.081.371 sampai Rp. 206.434.400 per tahun. Pendapatan petani sampel tertinggi di Desa Sialang Kayu Batu dipengaruhi oleh hasil usaha pertanian seperti 
luas lahan karet, kelapa sawit dan sebagainya serta usaha lain pertanian seperti dagang, perangkat desa dan lain lainnya. Tabel 4 menjelaskan proporsi pendapatan tertinggi petani di Desa Sialang Kayu Batu terdapat pada petani dengan golongan menengah sebanyak 9 orang dengan total proporsi jumlah pendapatan per tahun sebesar Rp.769.422.455 (41,06\%), dan pendapatan rata-rata rumah tangga dalam setahun sebesar Rp.85.491.384. Sedangkan untuk proporsi pendapatan terendah dalam setahun sebesar Rp. 409.293.513 (21,84\%) dengan rata-rata pendapatan dalam setahun sebesar Rp.45.477.057.

Pendekatan distribusi pendapatan melalui Indeks Gini Ratio menunjukkan adanya ketimpangan atau ketidakmerataan pendapatan antara petani responden. Berdasarkan Tabel 5 nilaiindeks Gini Ratio petani Eks UPP TCSDP di Desa Sialang Kayu Batu yaitu 0,20 berarti distribusi pendapatan berada pada ketimpangan rendah atau ringan. Artinya kemerataan pendapatan petani Eks UPP TCSDP di Desa Sialang Kayu Batu tergolong cukup baik, meskipun ada beberapa petani yang memiliki pendapatan yang tinggi. Pendapatan tertinggi dalam setahun yaitu Rp. 206.434.400 jauh dengan pendapatan petani terendah yaitu hanya sebesar Rp. 26.743.574 per tahun. Ketimpangan ini terjadi karena adanya perbedaan pendapatan sampingan dibidang pertanian maupun non pertanian.

Kurva Lorenz memperlihatkan hubungan kuantitatif antara persentase penerimaan pendapatan dan persentase total pendapatan yang diperoleh. Kurva Lorenz menyatakan bahwa semakin jauh jarak Kurva Lorenz diagonal (kemerataan sempurna) semakin tinggi tingkat ketidakmerataannya, artinya Kurva Lorenznya akan semakin mendekati sumbu horizontal.

Tabel 4. Distribusi Pendapatan Petani Eks UPPTCSDP Berdasarkan Kelompok Pendapatan Tahun 2016

\begin{tabular}{cccccc}
\hline No & Golongan & $\begin{array}{c}\text { JumlahSampel } \\
(\text { Jiwa })\end{array}$ & $\begin{array}{c}\text { Proporsi } \\
\text { Pendapatan } \\
(\mathrm{Rp})\end{array}$ & $\begin{array}{c}\text { Rata-rata } \\
\text { Pendapatan } \\
(\text { Rp/KK/Tahun })\end{array}$ & $\begin{array}{c}\text { Persentase } \\
(\%)\end{array}$ \\
\hline 1 & $40 \%$ terendah & 9 & 409.293 .513 & 45.477 .057 & 21,84 \\
2 & $40 \%$ menengah & 9 & 769.422 .455 & 85.491 .384 & 41,06 \\
3 & $20 \%$ tertinggi & 4 & 695.287 .933 & 173.821 .983 & 37,10 \\
\hline Total & & 22 & 1.874 .003 .901 & 304.790 .427 & 100,00 \\
\hline Sumber: & & & &
\end{tabular}

Sumber: Olahan Data Primer 2016

Tabel 5.Indeks Gini Ratio Petani Eks UPP TCSDP di Desa Sialang Kayu Batu

\begin{tabular}{|c|c|c|c|c|c|c|c|}
\hline No & $\begin{array}{l}\text { Golongan } \\
\text { Petani (Fi) }\end{array}$ & $\begin{array}{c}\text { Jumlah } \\
\text { Sampel } \\
\text { (Jiwa) }\end{array}$ & $\begin{array}{c}\text { Proporsi } \\
\text { Pendapatan } \\
\text { (Rp) }\end{array}$ & $\begin{array}{c}\text { Pendapatan } \\
\text { Dalam } \\
\text { Kelas }(\%)\end{array}$ & $\begin{array}{c}\text { Proporsi } \\
\text { Pendapatan } \\
\text { Kumulatif } \\
(\%)\end{array}$ & $\mathrm{Yi}+\mathrm{Y}-1$ & $\begin{array}{c}\mathrm{Fi} \\
(\mathrm{Yi}+\mathrm{Yi}-1)\end{array}$ \\
\hline 1 & $40 \%$ terendah & 9 & 409.293 .513 & 21,84 & 21,84 & 21,84 & 0,09 \\
\hline 2 & $\begin{array}{l}40 \% \\
\text { menengah }\end{array}$ & 9 & 769.422 .455 & 41,06 & 62,90 & 84,74 & 0,34 \\
\hline 3 & $20 \%$ tertinggi & 4 & 695.287 .983 & 37,10 & 100,00 & 184,74 & 0,37 \\
\hline & Total & 22 & 1.874 .003 .901 & 100 & & & 0,80 \\
\hline \multicolumn{7}{|c|}{ Indeks Gini Ratio } & 0,20 \\
\hline
\end{tabular}

Sumber: Olahan Data Primer 2016 
Suatu distribusi pendapatan dikatakan merata sempurna, bila kurva Lorenz berhimpitan dengan garis 45 derajat. Sebaliknya distribusi pendapatan dikatakan sangat timpang apabila Kurva Lorenz bergerak menjauhi garis 45 derajat.

Pada Gambar 1. menunjukkan bahwa penyebaran pendapatan petani Eks UPP TCSDP di Desa Sialang Kayu Batu relatif merata. Hal tersebut terlihat pada Kurva Lorenz yang mendekati garis diagonal atau garis kemerataan, maka semakin ringan tingkat ketimpangan antar golongan petani Eks UPP TCSDP di Desa Sialang Kayu Batu. Golongan pada $40 \%$ terendah menerima pendapatan $21,84 \%$ dari total pendapatan petani sampel, untuk golongan 40\% menengah mendapat $41,06 \%$ dari total pendapatan petani sampel dan $20 \%$ tertinggi mendapatkan $37,10 \%$ dari total pendapatan petani sampel di Desa Sialang Kayu Batu.

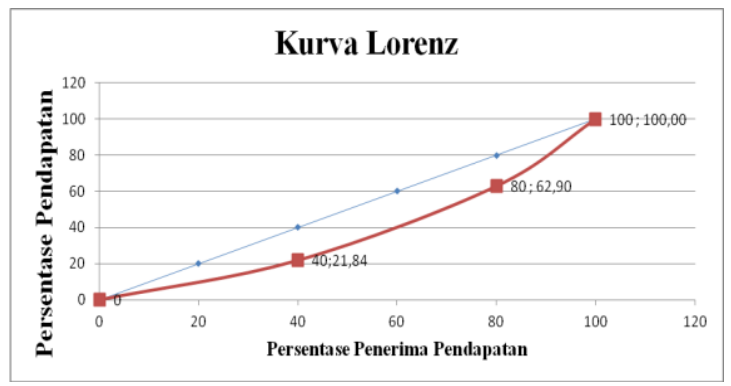

Gambar 1.Kurva Lorenz Pendapatan Petani Eks UPP TCSDP Desa Sialang Kayu Batu

\section{KESIMPULAN DAN SARAN}

\section{Kesimpulan}

1. Sumber pendapatan petani Eks UPP TCSDP di Desa Sialang Kayu Batu di Kecamatan Bunut Kabupaten Pelalawan dibagi menjadi dua yaitu pendapatan dari pertanian dan non pertanian, total pendapatan dari pertanian. diperoleh setahun sebesar Rp.1.685.603.901 (89,95\%) dengan rata-rata pendapatan per bulan sebesar Rp.140.466.992. Sedangkan total pendapatan yang berasal dari non pertanian per tahun sebesar Rp 188.400.000 (10,05\% ), dengan rata-rata pendapatan perbulan sebesar Rp 15.700.000. Total pendapatan petani Eks UPP TCSDP di Desa Sialang Kayu Batu dari pertanian dan non pertanian sebesar Rp. 1.874.003.901 per tahun dengan rata-rata pendapatan per tahun sebesar Rp.85.181.996.

2. Struktur pendapatan petani Eks UPP TCSDP Desa Sialang Kayu Batu dibagi menjadi dua sumber yaitu sumber pendapatan utama dansumber pendapatan sampingan. Struktur pendapatan yang diperoleh dari pendapatan utama Rp1.685.603.901 per tahun $(89,95 \%)$ dengan rata-rata pendapatan petani per bulan sebesar Rp. 6.384.863. Petani Eks UPP TCSDP di Desa Sialang Kayu Batu memperoleh pendapatan dari pekerjaan sampingan Rp. 188.400.000 per tahun $(10,05 \%)$ dengan rata-rata pendapatan petani per bulan sebesar Rp. 713.636.

3. Distribusi pendapatan tertinggi petani Eks UPP TCSDP di Desa Sialang Kayu Batu terdapat pada petani Eks UPP TCSDP dengan golongan menengah sebanyak 9 orang dengan total proporsi pendapatan per tahun sebesar Rp.769.422.455 (41,06\%) dengan pendapatan rata-rata sebesar Rp.85.491.384. Sedangkan untuk proporsi pendapatan terendah yaitu petani Eks UPP TCSDP golongan terendah sebanyak 9 orang dan total proporsi pendapatan sebesar Rp.409.293.513 per tahun (21,84\%) dengan rata-rata pendapatan setahun sebesar Rp.45.477.057. Indeks Gini Ratio Petani Eks UPP TCSDP di Desa Sialang Kayu Batu berada pada ketimpangan rendah atau ringan yaitu sebesar 0,20. Artinya kemerataan pendapatan petani Eks UPP TCSDP di Desa Sialang Kayu Batu baik.

\section{Saran}

1. Kepada petani Eks UPP TCSDP di Desa Sialang Kayu Batu karena tanaman karet sudah berusia 25 tahun agar segera melakukan penebangan dan penanaman ulang kebun karet TCSDP artinya memasuki fase tua bersifat kurang potensial, dalam meningkatkan produtivitas kebun karet baik itu kebun karet Eks UPP TCSDP maupun kebun karet swadaya dengan cara lebih meningkatkan pemeliharaan tanaman karet tersebut.

2. Berbagai sumber pendapatan serta kesempatan kerja yang potensial baik yang berasal dari pertanian dan non pertanian perlu lebih dikembangkan petani demi 
upaya meningkatkan pendapatan dan kesejahteraan rumah tangga petani karet.

3. Pemerintah Desa Sialang Kayu Batu untuk membuat kebijakan seperti pengadaan Koperasi Unit Desa guna menampung hasil produksi petani, karena selama ini para petani menjual produksinya kepada tengkulak yang berakibat pada penekanan harga jual ditingkat petani.

\section{DAFTAR PUSTAKA}

Badan Pusat Statistik. 2014. Data Sensus Pertanian 2013. Badan Pusat Statistik Provinsi Riau. Pekanbaru.

Badan Pusat Statistika. 2014. Kabupaten Pelalawan Dalam Angka 2014. BPS Kabupaten Pelalawan

Direktorat Jenderal Perkebunan. 2015 www.ditjenbun.pertanian.go.id/.Produksi Luas Areal dan Produktivitas Perkebunan Indonesia.Diakses pada tanggal 15 Desember 2016.
Eliza. Shorea Khaswarina. Arif Suganda. 2015. Distribusi Pendapatan Rumah Tangga Petani Karet di Desa Pulau Jambu Kecamatan Kuok Kabupaten Kampar.Jurnal Social Economics Agricultural Vol. 10 No. 2. Agustus 2015 ISSN 1693-4784 Halaman 117 127 Fakultas Pertanian Universitas Palangka Raya.

Suswatiningsih, Tri Endar. 2008. Keragaan Usahatani Karet Rakyat di Kabupaten Rokan Hulu Riau- The Porformance of Smallholder Rubber Farms in The Rokan Hulu Regency Riau. Buletin Ilmiah Instiper, volume 15: 6-14.

Soekartawi.2002. Prinsip Dasar Ekonomi Pertanian, Jakarta: PT Raja Grapindo Persada.

Widodo,S.T. 1990. Indikator Ekonomi Dasar Penghitungan Perekonomian. Kanisius. Yogyakarta. 